\title{
Perceptions of governance in the animal welfare sector
}

\begin{abstract}
Authors:
Dr Chantelle Murray ${ }^{1}$

Prof. Adèle Thomas ${ }^{1}$

Affiliation:

${ }^{1}$ University of Johannesburg, South

Africa

Corresponding author:

Prof. Adèle Thomas

adelet@uj.ac.za

DOI:

10.15249/13-2-222

\section{Keywords:}

animal shelters; charitable giving; donor trust; nonprofit sector; stakeholders
\end{abstract}

\section{Abstract}

The purpose of the study was to gather information on perceptions of the current governance practices in shelters in South Africa and put forward recommendations to professionalise the sector at board or committee level. Through semi-structured interviews, this qualitative study sought out the views of 16 participants, both at board or committee and at operational levels, at companion animal shelters. The main findings indicate inconsistencies and flaws in the governance fabric in this sector, and point to the need for a coherent set of basic governance standards suitable for shelters. This study makes a contribution to the companion animal welfare sector by offering the first formal study into governance in this domain and provides a foundation from which future research can be leveraged.

\section{Introduction}

The objective of the study was to identify perceptions of governance at South African companion animal shelters - something which no study has investigated to date. The article explores the experiences of 16 participants regarding shelter governance and operations. Sound governance that ensures transparent and professional functioning is crucial for improving donor trust and charitable giving, while supporting operational efficiency.

The non-profit organisation (NPO) sector in South Africa is large, diverse and multi-layered (Saifundraising, 2012). Within the collective landscape, which is coordinated by the Department of Social Development, there are different formal and informal organisations and numerous sub-sectors, each focused on a 
particular domain of human, animal or environmental need. The animal welfare sector fulfils an important role in the broader sphere of social development, which would not be balanced or sustainable if important aspects such as animal well-being and human-animal relationships were excluded from development programmes (World Animal Net, 2015). Their inclusion ensures the holistic development of humans, communities and societies. The American Society for the Prevention of Cruelty to Animals (ASPCA, 2012) categorises 'companion animals' as domesticated or domestic-bred animals that are companions in the home or exist in close relationships with humans.

Animal shelters focus on the sheltering, care, rehabilitation and re-homing of companion animals. Within the context of the challenge to raise funds and ensure sustainability, shelters are usually registered as non-profit organisations (NPOs) with the Department of Social Development. They must adhere to general governance principles as noted in the King IV Report (Institute of Directors, 2016) to ensure effective management, financial control, transparency and accountability, performance and results.

NPOs have increasingly stepped into socioeconomic and social service arenas worldwide, and need the professionalism, capacity and resources to remain true to their respective mandates while upholding good governance as they work with donor funding. In South Africa, the animal welfare sector enjoys little government and corporate funding support and struggles to survive. As such, the purpose of the study was to gather information on the current governance practices in shelters and put forward recommendations to professionalise the sector at board or committee level.

\section{Corporate governance}

Over the last 20 years, the ideology and adoption of corporate governance has spread rapidly around the globe, at both national and organisational levels (Aguilera \& CuervoCazurra, 2009). In broad terms, corporate governance is related to the framework of interwoven rights and responsibilities amongst stakeholders who have a vested interested in the organisation (Aoki, 2001), or the review of power and influence as it relates to the decision-making within the organisation (Aguilera \& Jackson, 2010). Codes of good governance can be viewed as a set of guidelines related to the functioning of the board of directors and other governance systems within the organisation in order to pursue best practices (Zattoni \& Cuomo, 2008). These codes, such as those noted in the King IV Report (Institute of Directors, 2016) have been developed to improve weaknesses in corporate governance systems by recommending a set of standards or norms aimed at improving transparency and accountability at executive and senior management levels (Fernandez-Rodriguez, Gomez-Anson \& Cuervo-Garcia, 2004).

Armstrong, Segal and Davis (2006) indicate that corporate governance in South Africa was formally introduced by the publication of the first King code (King I) in 1994. The King codes $(1994,2002,2009,2016)$ are based on the voluntary 'comply or explain' principle and require organisations to extend beyond the typical financial and regulatory reporting of corporate governance and take into account the interests and well-being of a range of 
stakeholders including local communities, employees and customers (West, 2009). The King IV code came into effect in 2017 and has a holistic outlook that views organisations operating according to "the triple context of the economy, society and the environment" (Institute of Directors, 2016:4). The listed governance principles and practices must be applicable across public, private and NPOs (Institute of Directors, 2016).

While corporate governance has been one of the key topics for a number of years in management practice and theory, the research-oriented analysis of governance in nonprofit settings is underdeveloped (Issa Gazi, 2012), thus underlining the importance of this study. McClellan (2014:253) states that "NPOs, as the mission-driven agents of change, are moving from the margins to the centre of our social fabric, especially as government spending on social programs as a proportion of total spending, decreases". NPOs are under escalating pressure to fill the void left by government in a wide range of social areas, and they now facilitate projects, funded by public money, that were previously handled by government (Verschuere \& Beddeleem, 2013).

With this as context, more and more NPOs have to prove that they have efficient and effective governance structures (Du Bois, Caers, Jegers, De Cooman, De Gieter \& Pepermans, 2007). Wells (2012) confirms that there is no doubt that the credibility of NPOs is positively linked to good governance, and that this, in turn, has a positive link to obtaining funding to achieve objectives.

\section{Companion animal welfare in South Africa}

In South Africa, the SPCA movement, which began in 1955, operates under the leadership of the National Society for the Prevention of Cruelty to Animals (NSPCA). Over the years, the animal welfare cause in this country has given rise to a proliferation of diverse types of private organisations. However, the SPCA movement remains the largest formal organisation in the field.

Given South Africa's apartheid past and the need for government to address historic disadvantages and socioeconomic inequalities, the animal welfare sector needs to proactively drive its own sustainability. The lack of a coherent government response to the various animal welfare challenges in this country, coupled with the absence of government funding in the sector and the omission of animal welfare from corporate social investment priorities, indicates that that the sector is 'on its own' at this point in time. The draft report of the Department of Agriculture, Forestry and Fisheries (DAFF, 2015:3) states that "South Africa does not have any comprehensive legislation that addresses all animal welfare needs ... The current legislation is fragmented...".

The literature review, too, revealed no formal studies relating to the sector landscape, its governance practices or its level of donor investment. Such a lack of formalised research attests to the fact that this sector has not been a priority in terms research or allocation of funding. 


\section{Research design}

The objective of the study was to identify perceptions of governance at South African companion animal shelters.

\subsection{Method}

This study used a qualitative research design to collect data, analyse the findings and provide insight about governance practices in the companion animal welfare sector in South Africa. The fieldwork was facilitated over a single phase of data gathering, drawing on semi-structured interviews to engage with participants.

\subsection{Sampling}

The population included all board or committee members, shelter staff and volunteers involved in two public (SPCA) and two private shelters. SPCAs are shelters that fall under the SPCA Act and that are obligated to accept every animal surrendered into their care. Private shelters that came into being after the SPCA era, are not supported by the SPCA Act and are not obliged to accept every animal referred to their service. This population is directly involved or indirectly involved (such as a volunteer fundraiser) in the operations of a shelter. A purposive sample of 16 participants was drawn from this population.

A consideration underpinning the choice of sampling approach was to ensure a crosssection (or strata) of participants (volunteers, board members, employees of the organisation) across all organisations so that a diversity of views and experiences could be incorporated into the study.

The following criteria constituted the basis for the selection of the four participating shelters and participants:

- The organisation had to be classified as a 'shelter', in other words, have the facilities and operating practices that facilitate the housing and care of companion animals for purposes of safe-keeping, rehabilitation and/or re-homing;

- The shelter had to be registered as a non-profit organisation (NPO) or non-profit company (NPC), and fall into either the public or private shelter domain;

- The shelter had to be in existence for longer than two years;

- The shelter had to have established a known brand, being known to local communities and wider afield as opposed to informal shelters that are not registered and that operate informally from a home base; and

- The shelter had to be of such a size (in terms of employees and volunteers) that participants could be selected at board or committee, management, specialised staff, volunteer and donor levels. 


\subsection{Data analysis}

The qualitative data were reviewed line by line, and in detail. As a recurring concept became apparent, a code or label to help catalogue and cluster key concepts was assigned to that segment of the document while preserving the original context in which these concepts occur (Miles \& Huberman, 1994). The list of codes in the transcriptions were recorded and compared - this was an iterative and dynamic process of sifting, comparing and filtering. This process culminated in the identification of five dominant themes common across the interviews.

\subsection{Ethics}

In ensuring clear information about the study, the researchers sent a letter to all chairpersons of shelter committees several months before the fieldwork started. This letter was disseminated amongst the targeted strata at each shelter and participation was voluntary.

The fieldwork approach focused on ensuring psychological security and confidentiality. Interviews were scheduled at venues and times that suited each participant, and participants were free to speak their minds without fear of negative consequences. Each participant had the opportunity to decline the use of a recording device if they were not comfortable with such.

Participants were advised that they would receive a summarised report of the overall research findings and that all references to any specific individuals or shelter would be replaced by a generic overview of the emerging patterns and trends.

\section{Findings}

Five dominant themes emerged from the data.

\subsection{Theme 1: Ethical leadership}

\subsubsection{The constitution as baseline for ethical leadership}

The interviews revealed a variable understanding and awareness of the influence of the organisational constitution on the functioning of the board or committee and shelter. A response that reflected this position is as follows:

I don't know if we are adhering to the constitution the way we should, for example, in terms of structure. I'm not sure if committee members have even read through it or understood it.

(Participant 5: Inspector/committee member, private shelter)

The public shelters (SPCAs) resort under a constitution generated by their national governing body - the NSPCA. Despite this structuring, however, the responses did not demonstrate understanding with regard to the purpose, content and application of the 
constitution. Private shelters generate their own constitutions as part of the process of registering as NPOs. However, the responses suggested that adherence to the constitution is often a compliance exercise, and that the constitution is not necessarily implemented daily in terms of organisational decision-making, procedures and ethos.

\subsubsection{Conflicts of interest, the balance of power and the role of the chairperson}

The lack of centrality of the constitution in the functioning of the board or committee opened up a number of controversial issues related to governance. One of these issues was the occurrence of the 'founder's syndrome', a situation in which a founder member overstays his or her welcome at the helm of an organisation.

You know all about 'founder's syndrome'? Our founder was a typical example. It was her place and no-one was going to get rid of her. She was stealing money. It took the board of directors and one person with enormous guts to eventually work her out - it was one of the worst fights I have ever seen in my life.

(Participant 4: Managing director/board member, private shelter)

The responses pointed to a dominant power that resides within the founder member or the chairperson, and which remains unchecked in the absence of a clear constitution that is widely understood and enforced by all board or committee members.

\subsubsection{Election of board members and composition of the board or committee}

Participants grappled with what it means to be ethical and sufficiently transparent to the public while still adhering to a governance model that works in practical terms. The governing boards/committees of shelters often consist of a hybrid collection of volunteers from the public and internal animal welfare staff or representatives from the shelter itself. However, this approach is proving difficult, given the rapid turnover of committee members and prevailing conflict situations.

In many NPOs, friends and family get elected onto the board or committee in the absence of willing volunteers or nominations from the public sphere. This is certainly not an ideal situation. It is important to keep a professional and arms-length approach to board relationships. (Participant 4: Managing director/board member, private shelter)

All participants indicated that there were challenges in bringing together the right people from both the public and the animal welfare environments.

There is no time limit by which a chair must step down. I have been here for four years now. Committees must be re-elected at the annual general meeting but these AGMs are poorly attended, if at all.

(Participant 3: Chairperson, public shelter)

As such, both the composition of effective boards or committees, as well as the election of representatives, remains challenging in this sector. 


\subsubsection{Board representation}

This theme emerged from the discussion of the election of representatives and the composition of the board or committee.

Practically, making use of HoDs [heads of departments] does help because we can run our operations well without committee 'interference'. However, we talk about a lot of the same things and we do not have fresh perspectives, new skill sets and other ideas.

(Participant 1: Shelter manager/committee member, private shelter)

One of the private shelters relies only on its management committee for governance and operational requirements. This is cause for concern given the exclusion of external or public representatives from a transparent committee structure. Another private shelter opted to have only the managing director of the shelter on the board, together with skilled professionals who were specifically sought out and recruited. This structure has demonstrated operational merits. However, the manner in which the professionals were selected and recruited may be open to question.

We specifically sought out our board members for their skills. We had a need for an accounting person, an advocate, a business person, a CSR person, and then, of course, the inclusion of the MD of the shelter.

(Participant 4: Managing director/board member, private shelter)

From the feedback received, the formula and process for selecting people to serve on the board or committee, is inconsistent and requires improvement.

\subsubsection{Roles}

The following comprised generic roles within the board or committee structure: chairperson; vice-chairperson; treasurer; and secretary. This was particularly true for shelters in the public domain (the SPCAs). The formalisation of these roles was also dependent on the size of the shelter - the bigger the shelter, the more formalised the board or committee, and the better the chances of all four roles being present. In smaller public or private shelters, it was more common to find one person fulfilling more than one role. This raises concerns from a governance point of view.

In the absence of active support from the public, non-attendance at meetings by members, conflict between volunteers and animal welfare staff on the board or committee, and a lack of options as far as suitably skilled and available candidates is concerned, the committee roles become cosmetic in nature, extinct, or remain vacant for extended periods. From a governance perspective, this creates an opportunity for founding members or chairpersons to 'abuse' the leeway created as a result.

\subsubsection{Capacity challenges}

Capacity, both in terms of numbers and the quality of willing or skilled people is a critical factor in the effective governance of companion animal shelters in this country. 
If you look at the shelters, we are battling with governance because we just cannot get people to volunteer on our committees.

(Participant 1: Shelter manager/committee member, public shelter)

Given the lack of government funding support for the sector, the difficult nature of animal welfare work and the challenges of being able to remunerate individuals competitively, shelters struggle to retain competent people and may often end up keeping individuals who are not suited to the job. The same principle applies to individuals fulfilling governance roles at board or committee level - as long as the roles are filled, or the committee is able to function in some basic way, it will continue to exist or operate in some rudimentary form. This drops the standards of governance within the sector.

\subsubsection{Performance evaluation of the board or committee}

Given that the companion animal welfare sector has little to no professional support functions within shelters, it emerges that there is limited (or no) performance evaluation of members of boards/committees.

In our case, our management team also constitutes our committee. The focus of our performance appraisals is on us as operational staff, not on us as a committee. These are hit-and-miss appraisals. The chairperson of our committee is also the managing director of our organisation, and he has no performance appraisal aimed at evaluating himself.

(Participant 1: Shelter manager/committee member, private shelter)

If performance evaluations happen at all, they happen at the staff level within the shelter, but not at board or committee level.

\subsubsection{Strategy and risk management}

The topics of strategy and risk management seemed to have caught participants offguard. Their focus was on the current reality and getting through the challenges from day to day.

You are often so bogged down by the enormity of the task that strategy falls away. This country has a huge problem. We cannot possibly grow any more, and the need just doesn't get less. (Participant 4: Managing director/board member, private shelter).

Only the two shelters that had included specialists from the corporate environment were able to confirm that strategy and risk management formed part of their meeting agendas.

\subsubsection{Orientation and training of board or committee members}

Incoming board or committee members are generally not familiar with the governance responsibilities required at this level, nor are they aware of the unique dynamics and challenges of the companion animal welfare sector as regards legislation and practice. Succession planning was not implemented effectively and many incoming board or committee members joined when the previous board or committee was dissolved or dismissed. 
I attended a two-day course in which I got an overview of the NSPCA constitution and the Animals Protection Act (APA) at the NSPCA offices. That was it. There was no incorporation of broader matters, for example, the NPO Act or good governance practices. The course is not mandatory and I am the only one on our committee who has attended it.

(Participant 3: Chairperson, public shelter)

The lack of formalised succession planning, handover and orientation was noted to be a key factor in the turnover or dissolution of committees in this sector.

\subsubsection{Stakeholder identification and engagement}

In questions related to stakeholders it was apparent that participants were inwardly focused on their own immediate teams and, in the case of the SPCAs, their own societies and the NSPCA head office. Although the public were mentioned, the responses did not indicate an overt awareness of the value of the public as a key stakeholder and/or donor. Furthermore, stakeholders such as other shelters, corporates, veterinary organisations and government, were only highlighted by one participant.

Balancing stakeholder demands is challenging. I don't think anyone has ever really looked at who the stakeholders of the SPCA are. Our stakeholders would be our geographical community, employees, the animals, government (in particular, local government), and our donors.

(Participant 10: Chairperson, public shelter)

\subsubsection{The contracting of auditors}

All participants were aware of the importance of having an external auditing firm release an annual financial report. The process involved in selecting and appointing a particular auditing firm was, however, not clear. At one shelter, the chairperson selected the auditors and had them approved by the management committee. At another shelter, an auditing firm was selected and proposed at the AGM and approved through a majority vote. When participants were asked how they would know if a board member was receiving kickbacks from procuring a particular firm, the responses were similar:

If that was happening we would have no idea.

(Participant 1: Shelter manager/committee member, private shelter)

If shelters rely on decisions made at their AGMs, and these AGMs are poorly attended, it creates the possibility that one person/group can influence the decision about which auditing firm to use, and the nature of the annual reporting content.

\subsection{Theme 3: Collaboration}

\subsubsection{Volunteer programmes}

Given the lack of capacity within the sector, volunteerism and volunteers could be an important source of support and specialised skills. Despite this, the notion of using volunteers in shelters emerged as a controversial issue. 
Volunteers are often more of a liability than an asset. They don't understand how animal welfare works but come into a shelter and want to already give everyone instructions regarding how it should be done.

(Participant 2: Chairperson, private shelter)

\subsubsection{Peer collaboration and community empowerment}

NPOs are often characterised by a lack of capacity, funding and resources. As such, the pooling of resources, ideas, projects and special skills is useful. The feedback received, however, points to a sector where people struggle to work together.

If we could remove the impact of the ego from the equation, then maybe we could all work together - but it comes down to the pie and the number of players who all want a piece of the pie. Ideologies are different and this influences different policies across organisations.

(Participant 5: Inspector/committee member, private shelter)

Participant comments had specific bearing on relationships between public and private shelters. The inability to work together was said to have impeded the chances of shelters collaborating and pooling their resources. Although community outreach work and empowerment are important aspirations within the companion animal welfare sector, the reality points to the fact that shelters are struggling to make (their operational) ends meet. As a result, the full potential of joining forces to undertake outreach programmes in communities has not, as yet, been achieved.

\subsection{Theme 4: Financial sustainability of the organisation}

\subsubsection{Fundraising}

Given the broader national context, the animal welfare sector faces a challenge in securing funding streams to ensure both survival and sustainability.

We must find alternative income streams and this is important going forward. We need to think differently about fundraising and we need to reach new people.

(Participant 1: Shelter manager/committee member, private shelter)

Staff at shelters often lack the skills to be effective at fundraising and, as such, shelters need to strategise around a formula or approach that works. Competing for donor support from the public, given the proliferation of shelters with similar brands and offerings, was said to be a daunting task. The issue of government's lack of funding for animal welfare and, specifically, for companion animal welfare, was a recurring theme throughout the responses received.

\subsubsection{Donor relationship management}

The ability to attract donors and convert once-off benefactors into long-term supporters is critical in the non-profit sector. In this respect, feedback from the participants indicated that the companion animal welfare sector is still in its infancy as far as donor relationships are concerned. 
We have asked for sponsorships, or help with services for our vehicles, but we have not come right. The tough economy is a factor and people do not have money. People don't even pay visits to the shelters to see how things are run. All that we predominantly see is ad hoc giving - both in terms of funds and also products and food.

(Participant 7: Shelter manager/committee member, public shelter)

Linked to the struggle for capacity and the reality of the overwhelming pressure on companion animal welfare, shelters do not have coherent and structured donor management systems which could eventually result in them having to close down.

\subsection{Theme 5: Accountability to the public and to donors}

\subsubsection{The release of animal welfare performance statistics}

The absence of reporting statistics, particularly to the public, it was said, creates a climate in which information can be manipulated or withheld, and donations are channelled into shelters based on subjective opinions or distorted/incorrect information. The lack of performance statistics was noted to contribute to the retention of mediocre people and the promotion of poor performance.

Statistics should be released. A Section 21 is a public company and anything about it should be available. At present, we work on an accepted norm and no one from the public questions the status quo or asks for more information, or pushes the boundaries. I like the concept of releasing statistics in a structured manner because it will develop a healthy sense of competition, and develop and encourage shelters to be better.

(Participant 4: Managing director/board member, private shelter)

Participants were in favour of reporting performance statistics more widely and openly. They viewed the release of such data as important for educating the public, informing donors and engaging in constructive competition and development.

\subsubsection{The value of an external evaluation and rating agency}

In terms of innovative models of accountability and transparency in the non-profit sector, a neutral, external rating agency can serve a useful purpose in monitoring activity and reporting results to the public. The work rendered by an external rating agency can be central to donor decision-making, while fostering a climate of healthy productivity and competition between participants. At present, in South Africa, unlike in the United States, there is no such external rating agency for the companion animal welfare sector.

We all need to be more distinguishable and more accountable, and we need developmental feedback. Donors need to be able to weigh up whether this organisation needs more money than another organisation. We do our best to maintain a good space. However, our bills are high. We need to pay vets to sustain the services we run. So, it would be a way for the public to make a more informed decision.

(Participant 1: Shelter manager/committee member, private shelter) 
The study aimed to identify perceptions of governance at South African companion animal shelters. The five core themes which emerged during this phase are discussed below. They are: ethical leadership, effectiveness of the board or committee, collaboration, financial sustainability of the organisation, and accountability to the public and donors.

\subsection{Theme 1: Ethical leadership}

The constitution forms the bedrock at any organisation for the composition and activities of all boards/committees. Turnbull (2014) advocates that the manner in which an organisation is governed should be determined by its directors, as set out in its founding constitution and the laws and norms of the society in which the organisation operates, and as reflected in the abilities and behaviour of its management. The constitution is recognised as the pivotal baseline for good governance.

The lack of centrality of the constitution in the functioning of the board or committee opens up a number of controversial issues related to governance. Without adherence to a constitution to provide an objective and clearly articulated baseline of rules and principles, human subjectivity enters the equation and creates weaknesses within governance systems (Chikadzi, 2013).

In shifting the focus of ethical leadership to the need to manage conflicts of interest and the balance of power within a board or committee, the need for a clear, comprehensive and 'lived' constitution factors into the equation. A constitution offers guidelines for effecting a balance of power within governing structures, and implementing mechanisms that allow for rigorous performance evaluation, development and rotation, where required.

Given the absence of shareholders, the implementation of the constitution relies wholly on the board (or some other group authority) to periodically elect board members. This is rarely done, however, as most boards become self-perpetuating (Dent, 2014). These factors, taken together, all affect the balance of power in NPO boards.

Companion animal shelters are struggling to attract skilled professionals from the external environment. As a result, friends and even family members may be nominated to fill a void, so that committees can function at the minimum level of representation. Alternatively, the same groups of people can entrench themselves in committees for lengthy periods of time, and thus negatively affect succession planning and the introduction of innovative ideas. Turnbull (2014) advises that the constitution must ideally denote a separation of powers between those who manage and those who govern, since such a demarcation helps to avoid systematic conflicts of interest and prevent unethical practices.

The companion animal shelter network is not at the level of strategic sophistication outlined in the governance literature. There appears to be no coherent or common view with regards to the election of board members. 
For those public shelters that still make use of the traditional combination of public and shelter-specific representation, there is a reliance on AGMs to solicit committee member nominations from the citizenry. Unfortunately, AGMs tend to be poorly attended (or not attended at all) and, as a result, representation on committees may remain unchanged for years, hampering opportunities to identify and recruit new talent.

\subsection{Theme 2: Effectiveness of the board or committee}

Hudson (2017) emphasises the importance of clearly defined roles at board or committee level - both in terms of the role fulfilled by every individual serving on the board and the role of the board itself. The board must have a clear understanding of its roles and responsibilities within the organisation if it is to function effectively within the power structure (Cornforth, 2001).

Within the shelter context, key roles usually include those of chairperson, vicechairperson, treasurer and secretary, along with other general members. Shelters are not attracting the requisite level of skilled executive and volunteer support. As a result, it is commonplace to find a single individual fulfilling two or more roles at board or committee level. This has implications for the balanced composition of a board or committee and, by implication, its level of efficiency. It also raises questions about the checks and balances needed to prevent unethical practices.

Nicholson, Newton and McGregor-Lowndes (2012) have demonstrated the positive relationship between NPO board performance and NPO effectiveness and Bright (2001) explains that board performance creates a framework for the success or failure of an organisation. The findings suggest that no formal performance evaluations exist for shelter boards/committees. Griffin, Larcker, Miles and Tayan (2017) emphasise that people do not join boards knowing how to be effective directors and therefore it is important that these individuals learn how to become effective. Taysir and Taysir (2012) note that board members must have the competence to enact the constitution of the NPO and pursue the mission of the organisation.

The findings indicate that strategy and risk management are not yet fully practised or developed within the sector. Given the reactive focus and the struggle for survival, activities tend to be short term and ad hoc in nature. With dependence on funding, and the irregularity and instability of funding streams, shelters are challenged in their ability to envision the future and plan their longer-term goals.

In linking strategic management and risk management, an NPO incurs increasing risk if it is unable to engage in strategic planning and delivery. Shelters must be able to pre-empt and navigate turbulence in both the sector and society in order to position themselves in such a way that they can utilise opportunities and minimise risk. However, given the scale of the animal welfare volumes referred to by participants, shelters have not been able to 'get ahead' of their daily challenges.

The findings suggest that shelters are not necessarily clear on who their stakeholders are, nor has anyone yet undertaken a formal 'mapping' of all the relevant parties. This lack of 
certainty immediately places shelters on the back foot in terms of their ability to tailor communication messages to specific audiences, or to involve stakeholders in strategic planning and consultation. Furthermore, in terms of stakeholder theory (Freeman, 1984), uncertainty regarding the profile of shelter stakeholders indicates that these entities have not yet fully explored the opportunities inherent in a stakeholder approach to governance.

Stakeholders represent a source of uncertainty for NPOs, since non-profits require resources and legitimacy from their stakeholders, but neither aspect is necessarily predictable nor controllable (Bielefeld, 2013). Stakeholder relationships need continuous and proactive monitoring and managing (Balser \& McClusky, 2005).

Although financial controls and reporting are fiduciary responsibilities of which NPO boards/committees are aware, the greatest challenge affecting this area of governance involves a lack of resources (Baapogmah, Meyer, Chien \& Afolabi, 2015). Given the rapid development of easily accessible media in the developing world, the demand for transparency and accountability on the part of charities is unavoidable. According to Bottiglieri, Koleski and Conway (2011), transparency that results in more satisfied donors correlates with increased donations and more effective NPOs. Sacco and Nagy (2004) assert that NPOs cannot expedite their public service missions faithfully without a transparent accounting system that provides sufficient information to the board, the public, donors and the state. Poor performance in accounting and management control will lead to a possible loss of faith and breach of trust in this sector.

\subsection{Theme 3: Collaboration}

Keeping volunteers committed and engaged is amongst the most difficult challenges facing NPOs. The organisational climate mediates the relationship between autonomous motivation and satisfaction, as well as that between external motivation and the intention to leave an organisation (Nencini, Romaioli \& Meneghini, 2016). The increasingly precarious employment relationships in NPOs can be expected to manifest themselves in the negative or detrimental employee responses identified in non-profit workplaces - examples include low morale and commitment, and ill health (Baines \& Cunningham, 2011). According to Kuttner (2008), high levels of turnover are an industry standard for casual, low-paid, human-service jobs such as those performed by NPO employees and volunteers.

At the board or committee level, the challenge is to attract and retain skilled professionals within the non-profit environment, and, particularly, the companion animal welfare sector. Boards/committees must function in such a way that people feel they are contributing to a mission with which they can identify, and that their skills and inputs are valued and make a tangible contribution. This is essential for ensuring a stable, effective and efficient board or committee. 
The findings point to shelter board or committee climates often being turbulent or downright hostile. Many of those from private shelters lamented their founding members overstaying their welcome, and general infighting amongst representatives.

A key challenge, therefore, is to support boards/committees so that they can achieve their full potential, rather than being characterised by strife or absenteeism. Linking back to the discussion on the orientation and training of incoming members, this 'coming together' at the outset would serve a useful purpose in creating common ground, providing clarity on roles and expectations, and arriving at an understanding of shelter and animal welfare realities. In the absence of proper orientation and further training, the divide between 'us and them' runs the risk of becoming more pronounced.

Participants were explicit about the lack of professional qualifications within the animal welfare sector, as well as the general lack of training and growth opportunities. These sentiments also apply to board or committee members who need a solid grounding in this sector and its concomitant challenges, as well as a comprehensive orientation regarding the applicable legislation and procedural rules.

The decision to commit to voluntary work and to an NPO is the result of a combination of prior experience, existing interests, social bonds and available information. If the decision is thus linked to specific motives and expectations, practical activities must satisfy these expectations, otherwise the commitment has no meaning (Penner, Dovidio, Piliavin \& Schroeder, 2005). Volunteer satisfaction also depends on whether the goals of the NPO are being met: failing to attain a common goal or encountering difficulties in meeting that goal chips away at commitment and motivation (Vecina, Chacón, Marzana \& Marta, 2013).

The findings indicate that some shelters regard volunteer programmes as a liability rather than an asset. Ironically, shelters are in need of additional capacity, given constraints at the human and resource levels. Volunteers, when oriented and involved in optimal and structured ways, have the potential to bring both human capacity and additional resources into this environment. If volunteers are not trained or seek to put their own needs above those of the organisation, they can become a liability.

MacIndoe and Sullivan (2014) report on non-profit stakeholders who urge within-sector (specifically, with other non-profits) and cross-sector (specifically, with for-profit firms and government agencies) collaboration as a way of achieving efficiencies in service delivery, stretching donor funding and improving their long-term sustainability. Calls for increased non-profit collaboration resonate with a proliferation in the number of non-profits, the duplication of organisational efforts, and geographic overlap in service delivery as threats to non-profit sustainability (Paarlberg \& Varda, 2009).

The findings indicate that shelters in South Africa are competitive, particularly given the limited financial donor pool. This is in line with the findings of Trussel and Parsons (2007), that financial sustainability issues are compounded by the existence of competition for funds amongst charities operating in the same areas. 


\subsection{Theme 4: Financial sustainability of the organisation}

NPOs must navigate fragmented funding streams, weather economic fluctuations, and contend with a variety of changes to their traditional revenue sources (Young, Peng, Ahlstrom, Bruton \& Jiang, 2008). In South Africa, given the lack of government funding and the negligible to non-existent funding from corporates, the companion animal welfare sector's biggest challenge (and threat) lies in a shelter's ability to raise sufficient funds to survive.

The effective functioning of the governing board or committee is vital in ensuring that the shelter facilitates effective fundraising, planning and the mobilisation of volunteers and ideas. Shelters must engage continuously with the public in order to build a brand name and reputation in the minds of actual and potential donors, and create a dependable supporter base and reliable funding streams.

The findings indicate that donor relationship management is still in an embryonic stage in the companion animal welfare sector. Shelters generally have ad hoc donor relationships and are hard-pressed to analyse and pursue purposeful relationship strategies, given the lack of staffing capacity and the operational volumes associated with welfare-related challenges.

\subsubsection{Theme 5: Accountability to the public and donors}

Shelters participate in compiling and submitting annual integrated financial statements pertaining to their NPO status and turnover. However, standard audit parameters focus on typical efficiency indicators associated with financial controls and management. Organisational sustainability necessitates social, environmental and economic performance measures (Schaltegger \& Wagner, 2017). In the case of the companion animal welfare sector, shelters would gain developmental value from broader audits that also evaluate operational efficiencies and welfare practices. At present, no entity is responsible for this level of monitoring and evaluation across both the public and private shelter networks. This is in direct contrast to the practice in the USA where inroads have been made over the past ten years with regard to the assessment and accountability of shelters through the combined influence of the Assilomar Accord (2004), Maddie's Fund, and charity ratings systems such as Charity Navigator and Guidestar (Heyde, 2008; McConnachie, 2007). These essentially constitute an interwoven system of basic standards on the one hand (Assilomar Accord, 2004; Maddie's Fund, 2015, Basic Data Matrix), and the purposeful measurement of performance in relation to standards (Maddie's Fund annual grant distribution activities), along with the release of statistics for public review to inform donor decision-making (Guidestar, Charity Navigator) on the other. 


\section{Recommendations and areas for future research}

Based on the findings of the study, the following main recommendations are furnished.

1. In a sector which is generally unable to draw in experienced professionals at the governance level, improved board or committee orientation and training are crucial. Consideration needs to be given to ways in which the sector can tap into the expertise of the private sector, in order to professionalise roles and access training.

2. Given the reality of capacity shortages at board or committee level, and the reality of the animal welfare challenge in this country, isolation and separation do not serve the best interests of the shelter community. It is important for the current fragmentation to be shifted towards an exploration of mutual synergies and pooled resources.

3. In South Africa, statistics are not readily available for the companion animal welfare sector. It is vital that NPOs explore various ways of adhering to requirements regarding transparency and accountability in this area of governance, particularly against the backdrop of the worldwide economic recession and increased competition to recruit and retain donors. Transparency and accountability work together to strengthen the consistency of management actions, thereby building credibility and trust (Szper \& Prakash, 2011). The combined process of performance rating and shelter development, expedited by a neutral, objective and external entity, should improve the transparency and accountability of shelter performance nationally, while providing concrete feedback and resources for growth and development. The additional benefit of releasing shelter performance results to the public could contribute to the education and information needs of the public, while allowing donors to make more informed decisions regarding charitable giving to any participating shelter. In turn, the empowerment of donors could facilitate greater accountability and responsibility amongst shelters in terms of animal welfare-related actions and financial spend.

Specific areas for future research in the area of volunteer management could include: research into the specific practices that will help to recruit and retain volunteers and allow shelter personnel to tap into their networks, research into the specific practices that are important for stakeholder engagement and the transparent communication with stakeholders and research into the need for an overall rating and co-ordinating body that could promote the working together of a fragmented sector as well as provide support for shelters as they grow from start-ups to established entities and beyond.

\section{Conclusion}

The study yielded a diversity of views across five governance themes, these being ethical leadership, effectiveness of the board or committee, collaboration, financial sustainability of the organisation, and accountability to the public and donors.

There is substantial scope in the companion animal welfare sector in South Africa to improve governance practices and better inform donors. The sector has been left to idle and in some instances, regress, due to a combination of weak legislation, insufficient 
funding, resources and infrastructure, a lack of government support, and the inability of participating shelters to come together to forge a better way forward. In the absence of a vibrant public presence, ranging from the attendance of annual general meetings and election of committee members, through to volunteerism and informed donor decisions, many shelters have continued unchecked - particularly with regard to the way in which boards and committees direct efficiencies, uphold performance and take accountability.

\section{References}

Aguilera, R.V. \& Cuervo-Cazurra, A. (2009). Codes of good governance. Corporate Governance: An International Review, 17(3):376-387. https://doi.org/10.1111/j.1467-8683.2009.00737.x

Aguilera, R.V. \& Jackson, G. (2010). Comparative and international corporate governance. Academy of Management Annals, 4(1):485-556. https://doi.org/10.5465/19416520.2010.495525

Aoki, M. (2001). Toward a comparative institutional analysis. Cambridge, MA: MIT Press. https://doi. org/10.7551/mitpress/6867.001.0001

Armstrong, P., Segal, N. \& Davis, B. (2006). Corporate governance in South Africa. In: C.A. Mallin (ed.). Handbook on international corporate governance. London \& Northampton: Edward Elgar. 210-230.

Asillomar Accord (2004). Shelter animals count. https://bit.ly/2LIXMcM [Accessed 13 June 2014].

ASPCA (American Society for the Prevention of Cruelty to Animals) (2012). ASPCA policy and positions. https://bit.ly/2qrqkKO [Accessed 11 April 2015].

Baapogmah, F.A., Mayer, R.W., Chien, W.W. \& Afolabi, A. (2015). Control mechanisms and accountability challenges in nonprofit organizations. Global Journal of Business Research, 9(1):27-38.

Balser, D. \& McClusky, J. (2005). Managing stakeholder relationships and nonprofit organization effectiveness. Nonprofit Management \& Leadership, 15(3):295-315. https://doi.org/10.1002/nml.70

Bielefeld, W. (2013). The role of accountability in fostering nonprofit integrity. In: W. Ammann (ed.). Integrity in organizations. London: Palgrave Macmillan. 174-191. https://doi.org/10.1057/9781137280350_9

Bottiglieri, W.A., Kroleski, S.L. \& Conway, K. (2011). The regulation of non-profit organizations. Journal of Business \& Economics Research, 9(9):51-60. https://doi.org/10.19030/jber.v9i9.5635

Bright, J. (2017). Action research consultation: Implementation of a performance management system within a non-profit organization. Unpublished doctoral dissertation. Texas: Angelo State University. https://bit. ly/2sFH6GD [Accessed 10 July 2017].

Chikadzi, V. (2013). Board of directors as a critical factor in the success of social enterprises. Journal of Community Positive Practices, 13(2):11.

Cornforth, C. (2001). What makes boards effective? An examination of the relationships between board inputs, structures, processes and effectiveness in non-profit organisations. Corporate Governance: An International Review, 9(3):217-227. https://doi.org/10.1111/1467-8683.00249

DAFF (Department of Agriculture, Forestry and Fisheries) (2015). Animal Welfare Strategic Implementation Plan to the Veterinary Strategy (Draft working group report) Directorate: Veterinary Public Health. https://bit.ly/2Yge1gS [Accessed 18 October 2016].

Dent, G.W. Jr (2014). Corporate governance without shareholders: A cautionary lesson from non-profit organizations. The Delaware Journal of Corporate Law, 39:93. https://doi.org/10.2139/ssrn.2285730

Du Bois, C., Caers, R., Jegers, M., De Cooman, R., De Gieter, S. \& Pepermans, R. (2007). The non-profit board: A concise review of the empirical literature. Journal for Public and Nonprofit Services, 30(1):78-88. https:// doi.org/10.5771/0344-9777-2007-1-78

Fernandez-Rodriguez, E., Gomez-Anson, S. \& Cuervo-Garcia, A. (2004). The stock market reaction to the introduction of best practices codes by Spanish firms. Corporate Governance: An International Review, 12(1):29-46. https://doi.org/10.1111/j. 1467-8683.2004.00341.x 
Freeman, R.E. 1984). Strategic management: A stakeholder approach. Boston, MA: Pitman/Ballinger.

Griffin, T., Larcker, D.F., Miles, S.A. \& Tayan, B. (2017). Board evaluations and boardroom dynamics. Stanford Closer Look Series. A corporate governance initiative. https://stanford.io/366ofDi [Accessed 10 July 2017].

Heyde, B. (2008). Evaluating the performance of animal shelters: An application of data envelopment analysis. https://bit.ly/2RmOvox [Accessed 20 April 2014].

Hudson, M. (2017). Managing without profit: Leadership, governance and management of civil society organisations. 4th edition. London: Directory of Social Change.

Institute of Directors (2016). King IV Report on Corporate Governance for South Africa. http://www.iodsa. co.za/ [Accessed 25 August 2017].

Issa Gazi, M. (2012). Social enterprise and good governance. ASA University Review, 6(2). https://bit.ly/2rX9bca [Accessed 20 October 2016].

Kuttner, R. (2008). Good jobs for Americans who help Americans. https://bit.ly/362GRnu [Accessed 11 July 2016].

MacIndoe, H. \& Sullivan, F. (2014). Nonprofit responses to financial uncertainty: How does financial vulnerability shape nonprofit collaboration? Journal of Management and Sustainability, 4(3):1-15. https:// doi.org/10.5539/jms.v4n3p1

Maddie's Fund (2015). Basic animal data matrix, 2015. https://bit.ly/2PeC77E; see also https://bit.ly/368vEC6 [Accessed 13 October 2015].

McClellan, C. (2014). Review of: Human resource management in the nonprofit sector: Passion, purpose and professionalism. The Philanthropist, 25(4). https://bit.ly/2RsZ49X [Accessed 10 July 2017].

McConnachie, L.K. (2007). Assessing performance of animal welfare organizations to improve philanthropic decision-making. Unpublished doctoral dissertation. Canada: University of British Columbia.

Saifundraising (2012). The Independent Code of Governance for NPOs in South Africa. https://bit.ly/388vix6 [Accessed 10 July 2015].

Nencini, A., Romaioli, D. \& Meneghini, A.M. (2016). Volunteer motivation and organizational climate: Factors that promote satisfaction and sustained volunteerism in NPOs. Voluntas: International Journal of Voluntary and Nonprofit Organizations, 27(2):618-639. https://doi.org/10.1007/s11266-015-9593-z

Nicholson, G., Newton, C. \& McGregor-Lowndes, M. (2012). The non-profit board as a team. Non-profit Management and Leadership, 22(4):461-481. https://doi.org/10.1002/nml.21040

Paarlberg, L.E. \& Varda, D.M. (2009). Community carrying capacity: A network perspective. Nonprofit and Voluntary Sector Quarterly, 38(4):597-613. https://doi.org/10.1177/0899764009333829

Penner, L.A., Dovidio, J.F., Piliavin, J.A. \& Schroeder, D.A. (2005). Prosocial behavior: Multilevel perspectives. Annual Review of Psychology, 56:365-392. https://doi.org/10.1146/annurev.psych.56.091103.070141

Sacco, J. \& Nagy, R. (2004). Accounting and management control in nonprofit organizations (NPO), accounting, reporting and management control. In: A. Zimmer \& P. Eckhard (eds.). Future of civil society: Making central European nonprofit-organizations work. Volume 1. Wiesbaden, Germany: VS Verlag für Sozialwissenschaften. 381-406. https://bit.ly/2Lm65W0 [Accessed 3 June 2015].

Schaltegger, S. \& Wagner, M. (2017). Managing the business case for sustainability: The integration of social, environmental and economic performance. New York \& London: Routledge. https://doi.org/10.4324/ 9781351280525

Szper, R. \& Prakash, A. (2011). Charity watchdogs and the limits of information-based regulation. Voluntas: International Journal of Voluntary and Nonprofit Organizations, 22(1):112-141. https://doi.org/10.1007/ s11266-010-9156-2

Taysir, E.A. \& Taysir, N.K. (2012). Measuring effectiveness in nonprofit organisations: An integration effort. Journal of Transnational Management, 17:220-235. https://doi.org/10.1080/15475778.2012.706736

Trussel, J.M. \& Parsons, L.M. (2007). Financial reporting factors affecting donations to charitable organizations. Advances in Accounting, 23:263-285. https://doi.org/10.1016/S0882-6110(07)23010-X 
Turnbull, S. (2014). It's time to replace toxic governance with good governance. 2 December. https://ssrn.com/ abstract $=2533220$ [Accessed 30 November 2016]. https://doi.org/10.2139/ssrn.2533220

Vecina, M.L., Chacón, F., Marzana, D. \& Marta, E. (2013). Volunteer engagement and organizational commitment in nonprofit organizations: What makes volunteers remain within organizations and feel happy? Journal of Community Psychology, 41(3):291-302. https://doi.org/10.1002/jcop.21530

Verschuere, B. \& Beddeleem, E. (2013). Organisational governance features, innovation and performance in NPOs: Existing evidence and future research directions. In: L. Gnan, A. Hinna \& F. Monteduro (eds.). Conceptualizing and researching governance in public and non-profit organizations. Bingley, UK: Emerald Group. 33-55. https://doi.org/10.1108/S2051-6630(2013)0000001006

Wells, P. (2012). The non-profit sector and its challenges for governance. Journal of Leadership, Accountability and Ethics, 9(2):83-93.

West, A. (2009). The ethics of corporate governance: A South African perspective. International Journal of Law and Management, 51(1):10-16. https://doi.org/10.1108/17542430910936637

World Animal Net (2015). Animal Welfare and Development: Potential Roles and Responsibilities of Multilateral Development Organisations, Financial Institutions and Governments. https://bit.ly/33KWK0o [Accessed 29 May 2018].

Young, M.N., Peng, M.W., Ahlstrom, D., Bruton, G.D. \& Jiang, Y. (2008). Corporate governance in emerging economies: A review of the principal-principal perspective. Journal of Management Studies, 45(1):196-220. https://doi.org/10.1111/j.1467-6486.2007.00752.x

Zattoni, A. \& Cuomo, F. (2008). Why adopt codes of good governance? A comparison of institutional and efficiency perspectives. Corporate Governance: An International Review, 16(1):1-15. https://doi.org/10.1111/ j.1467-8683.2008.00661.x 